\title{
Aspects of transport transit hubs construction management in coordination with object lifecycle projecting
}

\author{
Nina Danilina ${ }^{1 *}$, Denis Vlasov ${ }^{2}$ \\ ${ }^{1}$ Moscow State University of Civil Engineering, 129337, 26, Yaroslavskoye Shosse, \\ ${ }^{2}$ Genplan Moscow, Russia Institute of Moscow, 125047, 2/14, 2-nd Brestskaya str., Moscow, Russia
}

\begin{abstract}
The article involves the results of the research in the field of the initial phase in the project of the object lifecycle for urban public transportation transit hubs (TTH). The main purpose is to provide definition and justification of area parameters for spatial solution of a hub with consideration of its construction viability and sustainability of urban development. In the article there are presented the results of analytical studies of the data available in the approved Planning documentation for TTH objects listed in the short-term program of TTH construction in Moscow. The point of interest was to obtain correlations between the total area of TTH area, areas of commercial and technological use and passenger traffic value in order to define territory balance providing request from city authorities and private investors for construction project management. Also, there is presented the theoretical model as an evaluation guide that allows evaluating not only the demand of a city and its population in the development of TTH territory but also and especially the requirements for placing commercial areas inside TTH.
\end{abstract}

\section{Introduction}

The evolution of modern town planning relies on improving quality of urban environment according to people's diverse needs and abilities. Organization and management of construction processes that take place on the territories of the cities become the topical issues and require the development of long-term prospects. Currently, construction management system integrates a new object-oriented approach for the developing cities in the Russian Federation. It consists in the implementation of life cycle contracts for Construction project management [1]. Experts underline the effectiveness of such form of public-private partnership for design, construction, finance and operation of the key city facilities. The first stage of this contract consists in the development of project planning and design solutions and involves the development and approval of the Territory Planning Project and initial architectural and construction solutions of the object [2,3]. Information received with the completion of this stage serves the starting data for further stages of

\footnotetext{
Corresponding author: nina_danilina@mail.ru
} 
project development necessary to provide the highest quality of design decisions.

This article presents the results of the scientific research in the field of spatial and planning design solutions for the most complex urban integrated facility - public transport transit hub. The complexity of such object is determined by large variability of its components: different types of transport and objects of social, public, commercial, recreational infrastructures. That's why, the development of the regulatory support allowing to applicate the most rational and effective design solutions becomes one of the most important tasks that define the economic performance of the project needed both for private investors and city authorities $[4,5]$.

\section{Project objectives}

Spatial planning project of a transport transit hub (TTH) is intended to define the most efficient proportion of the spaces used by different types of facilities to the total area. Internal role of TTH within public transportation system and its placement in the functional urban areas composition determine the value of passenger traffic and its construction scale [6,7]. On this basis, it seems necessary to distinguish three basic groups of TTH:

1. Local public transport transit hubs. These are unimodal public transit hubs with a minimum rate of passenger traffic. They occupy small land area and their formation requires just local arrangements on the territories of road network and transport infrastructure objects.

2. Municipal public transport transit hubs. These are multimodal hubs with medium or high rate of transit passengers. The need for passenger transfer between different modes of transport requires a significant territorial resource in walking radius from the central passenger transport node - the station of the main type of passenger transport, especially when you need "Park and Ride" lots.

3. City, regional and other high-level public transport transit hubs with high and very high rates of passenger traffic. The central constructive element of these types of hubs is a transit terminal, which provides all internal transfer processes. The location of such terminal requires big spatial resource, and also causes the necessity for epy development of adjacent territories with a view to creating a high-quality urban space.

The third group of TTH is the most problematic one from the point of view of a number of transport, social, environmental and urban development problems caused by high rates of passenger traffic. So, these hubs are urban transport facilities of a priority interest for reconstruction or construction as for municipal authorities so for private investors. From investor's point of view such transport transit terminals are most attractive for development, offering prospects of the construction or reconstruction of a large scale object, group of objects, or zones of «transit oriented development». Alignment of interests makes such hubs most attractive for evaluation of their investment potential on the first level of construction project management by means of space planning and project design.

The availability of technological space defines the performance of the main transport service. Commerce areas are optional services to population, but their presence determines the investment interest in construction as thus its viability. The correct area ratio determines the sustainability of the entire facility in general. So, the main issue of the research becomes to determine the ratio between commercial and technological areas that attracts both city authorities and private sector investment. Composition of the areas is presented on figure 1. 


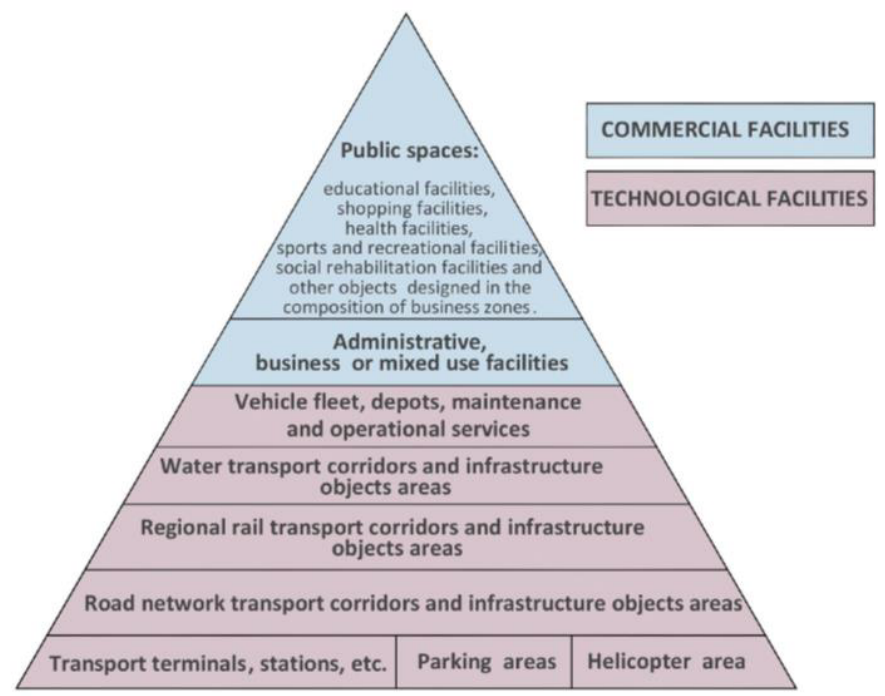

Fig. 1 Composition of transport hub areas.

The main data for the research was collected from official and approved planning projects of public transport hubs, designed in recent years in Moscow. Comparison of theoretical data and experimental survey results has provided interesting results. In the overall list (fig. 1) the proportion of transport technological facilities amounts to $85 \%$, so the percent of commercial facilities doesn't exceed $15 \%$. However, the survey analysis shows that in 22 approved projects with a total planning construction area over 1.8 million sq.m., only $16 \%$ of the area is allocated for technological purpose (fig. 2).

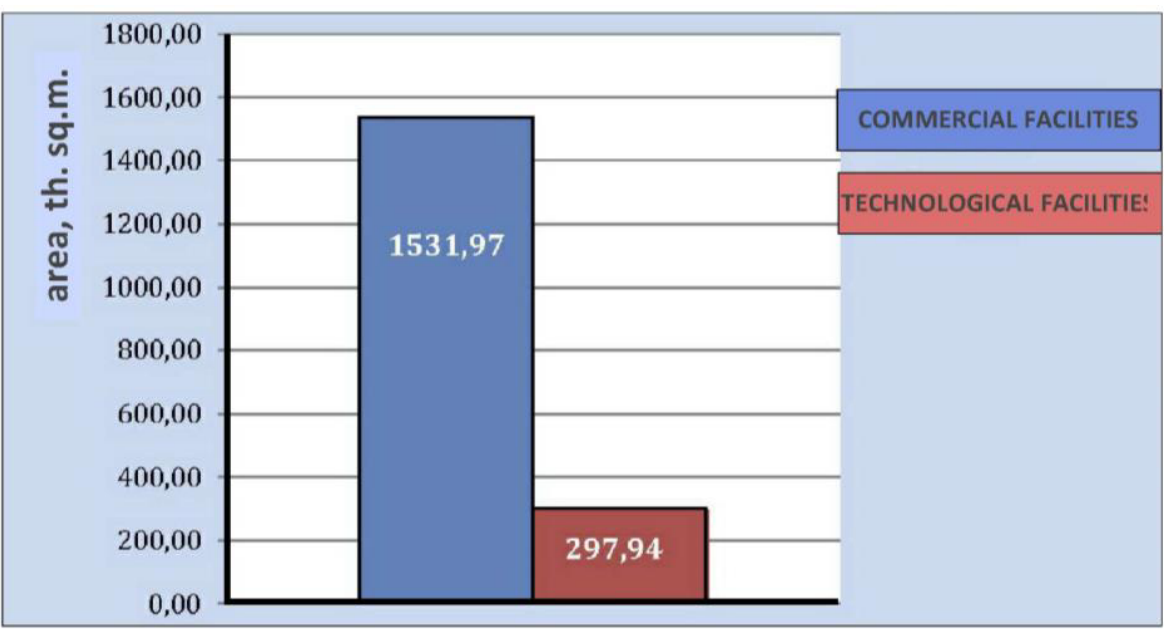

Fig. 2 Distribution graph of commercial and technological areas (according to approved Planning projects of transport hubs in Moscow).

Such data are an indicator of the interest of city authorities in attracting private investors for object life cycle management on the earliest stage of projecting process. In that case, it becomes necessary to find such correlation for the areas of the overall lot that allows both to satisfy public demand for transport services and to provide the investment attractiveness of the construction project. The practical significance of results obtained 
from such research studies is that they can be used for improvement of the regulatory framework for the development of hubs and for the elaboration of further planning projects.

\section{Data study}

In the experimental part of the study there was conducted the analysis of existing planning projects of transport hubs. To date, there've been approved 22 planning projects for transport hubs that constitute almost $10 \%$ of the total number of hubs in Moscow (table 1). So the aim of the study was to identify patterns in the spatial distribution of TTH resources.

Table 1.

\begin{tabular}{|c|c|c|c|c|c|c|}
\hline & & & Fac & ity area, ha & & Passenger \\
\hline & $\begin{array}{l}\text { Public transport } \\
\text { transit hub }\end{array}$ & $\begin{array}{l}\text { hub } \\
\text { area, } \\
\text { ha }\end{array}$ & $\begin{array}{l}\text { Technological } \\
\text { area, th. sq. } \mathrm{m}\end{array}$ & $\begin{array}{l}\text { Commercial } \\
\text { area, th. sq. } \\
\text { m }\end{array}$ & $\begin{array}{c}\text { Total } \\
\text { area, } \\
\text { th. sq. } \\
\text { m } \\
\end{array}$ & $\begin{array}{c}\text { traffic, } 1000 \\
\text { persons } \\
\text { /morning } \\
\text { peak hours } \\
\end{array}$ \\
\hline 1. & Alma - atinskaya & 57.24 & 0.64 & 84.37 & 85.01 & 26.20 \\
\hline 2. & Botanicheskiy sad & 15.52 & 36.43 & 141.30 & 177.73 & 44.00 \\
\hline 3. & Varshavskoe shosse & 23.73 & 13.47 & 25.50 & 38.97 & 16.20 \\
\hline 4. & Volgogradskaya & 44.71 & 9.76 & 0.00 & 9.76 & 18.80 \\
\hline 5. & Dubrovka & 44.71 & 11.62 & 0.00 & 11.62 & 25.60 \\
\hline 6. & ZIL (Park legend) & 13.87 & 17.63 & 93.09 & 110.72 & 17.00 \\
\hline 7. & Koptevo & 21.93 & 6.72 & 0.00 & 6.72 & 22.80 \\
\hline 8. & Kosino & 43.30 & 9.88 & 221.55 & 231.43 & 50.20 \\
\hline 9. & Lujniki & 6.90 & 6.05 & 0.00 & 6.05 & 24.90 \\
\hline 10. & Lubereckaya & 46.60 & 8.88 & 192.94 & 201.82 & 36.40 \\
\hline 11. & Novokosino & 47.40 & 8.14 & 94.22 & 102.36 & 58.00 \\
\hline 12. & Novochochlovskaya & 33.21 & 7.18 & 17.03 & 24.21 & 18.30 \\
\hline 13. & Paveleckaya & 13.43 & 0.56 & 131.96 & 132.52 & 67.80 \\
\hline 14. & Pyatnickoe shosse & 77.88 & 0.40 & 51.24 & 51.64 & 19.40 \\
\hline 15. & $\begin{array}{l}\text { Sevastopolskiy } \\
\text { prospekt }\end{array}$ & 14.32 & 14.47 & 0.00 & 14.47 & 26.60 \\
\hline 16. & Seligerskaya & 28.25 & 66.11 & 128.50 & 194.61 & 41.70 \\
\hline 17. & Sokolinaya gora & 19.70 & 8.05 & 40.00 & 48.05 & 12.00 \\
\hline 18. & Horoshevo & 7.56 & 7.66 & 0.00 & 7.66 & 9.20 \\
\hline 19. & Horoshevskaya & 53.00 & 44.60 & 141.60 & 186.20 & 46.60 \\
\hline 20. & Mitino & 21.49 & 7.98 & 26.86 & 34.84 & 14.80 \\
\hline 21. & Ryazanskaya & 30.10 & 29,60 & 121.00 & 150.60 & 78.30 \\
\hline 22. & Shipilovskaya & 13.80 & 12,04 & 20.76 & 32.80 & 10.50 \\
\hline
\end{tabular}

The analysis of the presented data reveals the following patterns:

- there is a certain correlation between technological and commercial areas and total area of a transport hub;

- there is a certain correlation between technological and commercial areas of a transport hub;

- there is a certain dependence of the commercial component volume on the value of passenger transit traffic through a hub during morning rush hour.

Each of the studied regularities is the supporting material for the initial phase of development of lifecycle management strategy for a particular public transport hub 
construction. Commercial component, its architecture and construction design as well as users projected passenger traffic are classified as techno-economic parameters of the project and define the investment attractiveness of the project for the private investor.

At the same time, the execution of transportation and urban formation functions by TTH is provided by sufficient amount of technological areas, ensuring passengers arrival, departure, transfer and waiting as well as the operational functioning of TPU and different types of transport infrastructure.

Value of facility area is received in the result of the Planning project data processing for every transport hub. Passenger traffic data refers to the total volume of passengers in arrival and departure for all modes of transport calculated and used by Moscow Master Plan Institute for the development of planning

Figure 3 provides the graph of correlation between technological and commercial areas and total area of transport hub, understood as the area within the boundaries of the site planning project. The problem is that these correlations are hardly to be used as a performance indicator, because today there are no clear guidelines on the definition of the boundaries of the area development plan and they are determined in negotiation with relevant city authorities. However, it is obvious that big proportion of commercial areas within TTH provides the interest of private investors and, in fact, the feasibility of project construction. That is why commercial areas are planned in 16 of 22 transport hubs, provided with documentation on territory planning.

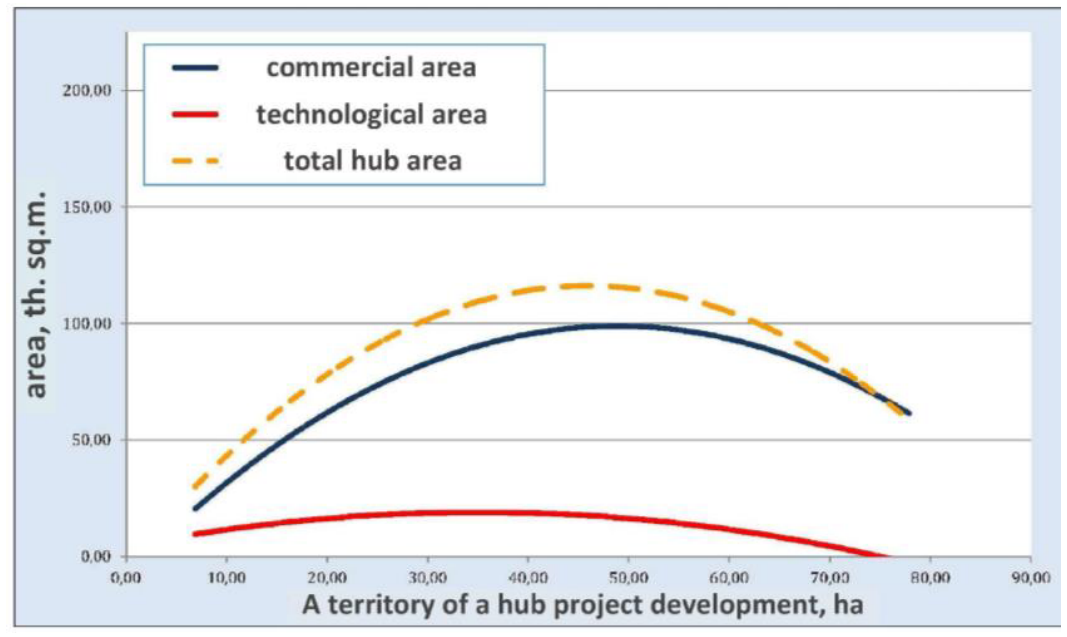

Fig. 3 Correlation between technological and commercial areas and total area of transport hub.

Therefore, the more rational is to use graph 3, reflecting the ratio of TTH area components to the passenger traffic passing through a hub during morning rush hour. As the previous one, it also looks as a parabolic curve. It should be emphasized that the curve referred to commercial facilities area and passenger traffic (shown in blue) has more pronounced curvature than the corresponding curve defined by technological area indicators (shown in red). This could be explained by the relatively small difference between minimum and maximum rates of technological facilities area. The nature of this ratio distribution is more uniform, and therefore, its value can be predicted more precisely than a ratio of commercial facilities area. Also worth noting is the overall lower values of technological facilities areas in comparison with the values in the areas of commercial facilities inside TTH. 
Analytical method used above, like all has advantages and disadvantages. The main advantage of this method seems to be that it clearly reflects a balance of two main groups of TTH areas, stimulating investment interest for the project both of city authorities and private investors. Such information obtained at object construction level is of significant value to guarantee for the viability of the project and transition to the next level of the life cycle contract development - further design stages of construction project.

The disadvantage of this method is that it does not offer a scientific approach to the problem of how to determine spatial decisions and focuses only on the importance of economically attractive factors, thus have limited application. To overcome this limitation, the development of theoretical and scientific method becomes useful based on systematic analysis of the complex urban planning factors that can ensure sustainable development of city objects and territories. The authors propose a model that reflects the dependence of the relationships of commercial and technological area spatial decisions on three integrated factors, such as:

- transport factor, that is estimated by the integrated index with consideration of territorial limits of the road network and passenger transport infrastructure objects;

- social and urban planning factors, that include main demand-oriented indicators concerning the demand of the city population for various functional facilities on particular urban areas;

- economic factor, that indicates the balance of expenditure and revenue parts of the project.

It should be emphasized that the sustainable development of urban transport system and creation of comfortable and safe environment on the territory of TTH depend directly on the functionality and convenience of technological-oriented area of a hub [8]. Regarded in that light, the task to determine the volume of commercial areas without harming the implementation of major transport, social and technological functions becomes one of the major issues on the initial development level of the life cycle of the construction project. The proposed model (fig.5) allows to divide the whole system into clusters, each of which may determine the availability of location, limits and functionality of commercial facilities.

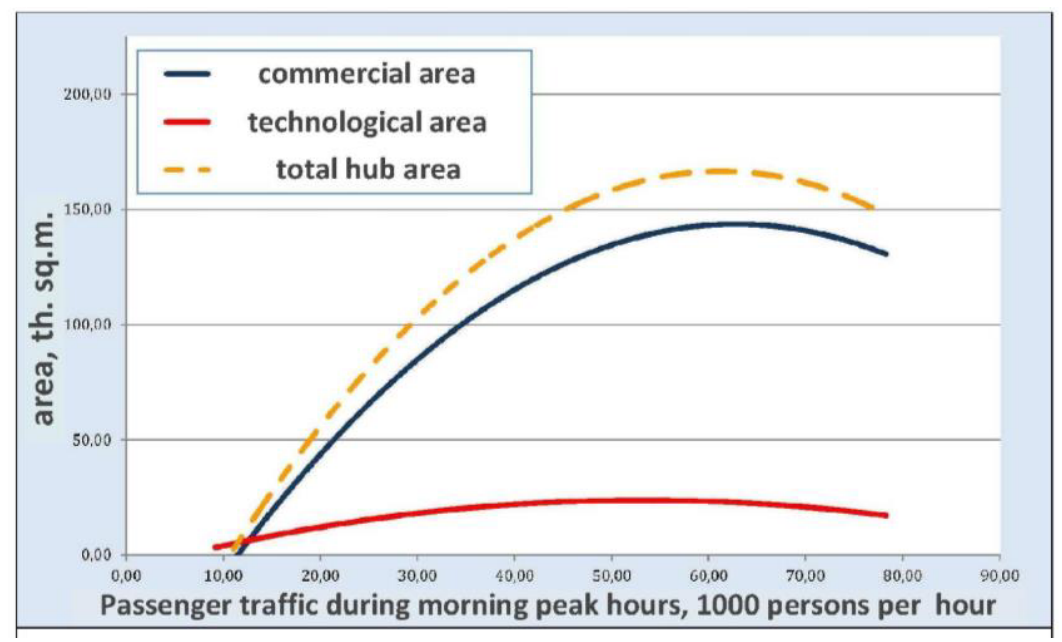

Fig.4 Dependence of the area components on the value of passenger transit traffic.

The rationales for placing the commercial component are the maximum values of all factors specific for the 3rd group of TTH with a need for transit terminal placement. This 
model is justified as it is based on the methods of scientific research as well as multifactorial analysis of the functioning of the construction sites in urban environment. A clear advantage of this model is that it offers the possibility to determine balance of interests between the city authorities and private investors - on the one hand, and population on the other, which is extremely important for development of modern highquality urban environment $[9,10]$.

\section{Conclusions}

The results of a research study determine the dependencies that can be used at the initial stage of the development life cycle of a city public transport transit hub aiming to make reasonable decisions for spatial-planning project design. Such stage is absolutely necessary to calculate the main technical and economic parameters of the project and its transition to further stages of construction development and project documentation design. The main results obtained in the study can be summarized in the following:

1. Analytical dependencies of ratios of commercial and technological areas within TTH, serving urban authorities and private investors a source data to show investment attractiveness of the construction project and mutual interest and understanding. It should be underlined that these data surely need to be updated in the next phase, addressing the urban planning as well as social needs of the population.

2. Theoretical model of commercial and technological areas distribution ensuring sustainability of urban construction and quality, and safety of the environment.

The results of these studies may provide adequate scientific justification at the development of regulatory support documents having regional and Federal value and allow for the methodical insurance of urban and transport planning process and transport transit hubs design. These data also forms the basis of further study, or experimental research.

\section{References}

1. E. Dorohina, Intern. journal of appl. and fung. 4-3, 652-652 (2016)

2. D. A. Kudelina, Conf. paper, Econom. and manag.: actual asp. of theory and practice, 92-95 (2015)

3. E. G. Irwin, Journal of Regional Science 50(1), 65-91 (2010)

4. J. Bröcker, A. Korzhenevych, C. Schürmann, Transp. Res. Part B 44(7), (2010)

5. N. Daniina, Conf. paper, Social - economic probl. and tend. of territ. develop., 39-43 (2016)

6. S. Gelareh, R. Neamatian Monemi, Nickel, Transp. Res. Part E 75, 67-94 (2015)

7. M. E. O’Kelly, H. J. Miller, Journal of Transport Geography 2(1), 31-40 (1994)

8. E. Sherbina, N. Danilina, D. Vlasov, Int. Jour. of Appl. Engin.Res. 10(22), 973-4562 (2015)

9. D. Vlasov, Modern probl. of science and educ. 4, 65 (2013)

10. D. Vlasov, Real estate: econom., manag. 1, 57-61 (2011) 